\title{
ENTREVISTA COM A JORNALISTA E ESCRITORA MARIA PILLA
}

INTERVIEW WITH JOURNALIST AND WRITER MARIA PILLA

\author{
DOI 10.20873/uft2179-3948.2021v12n2p275-285
}

\section{Gínia Maria Gomes ${ }^{1}$ Cristiane da Silva Alves ${ }^{2}$}

Entrevistamos para esse dossiê da ENTRELETRAS a jornalista e escritora Maria Pilla. Gaúcha, nascida "numa manhã de inverno de 1946”, como ela própria informa, Maria Regina Jacob Pilla iniciou seus estudos no Grupo Escolar Octávio Rocha, cursou o ginásio no Instituto de Educação e o então chamado científico no Colégio Estadual Júlio de Castilhos, todas escolas públicas. Na conclusão do penúltimo ano do ensino médio, candidatou-se a uma bolsa do Field Service e, obtendo-a, foi para os Estados Unidos, em 1963. Concluiu o Colegial na escola de Walnut Hills, em Cincinnati, Ohio, onde estava quando ocorreram o assassinato do presidente Kennedy e o golpe militar de 64 no Brasil. Ao voltar, passou no vestibular da Universidade Federal do Rio Grande do Sul (UFRGS) e entrou no curso de jornalismo, onde permaneceu até sair do país. No início do seu primeiro semestre na faculdade, ingressou no Partido Comunista Brasileiro e, logo depois, na Dissidência do RS, que se formava. Em seguida, participou da fundação do Partido Operário Comunista, o POC. Em 1970, suas atividades militantes clandestinas a obrigaram a sair de Porto Alegre e, depois, de São Paulo. Foi para a França, onde começou a militar na IV Internacional. Da França, foi para a Argentina, militar no Partido Revolucionário de los Trabajadores. Em 1975, foi presa em Buenos Aires e torturada pela polícia federal argentina. Esteve pouco mais de dois anos detida nas prisões de Olmos, na província, e de Villa Devoto, na cidade de Buenos Aires. Como estrangeira, ao ser libertada da prisão, no início de 1978, foi expulsa da Argentina para a França, tendo recebido asilo do governo francês. Residiu e trabalhou em Paris, por mais de quinze anos, na área gráfica. Depois

\footnotetext{
${ }^{1}$ Professora Titular de Literatura Brasileira no Instituto de Letras da Universidade Federal do Rio Grande do Sul (UFRGS). Doutora em Letras pela Universidade Federal do Rio Grande do Sul (UFRGS), realizou estágio pósdoutoral pela Paris III - Sorbonne Nouvelle (2009 e 2019-2020). Atualmente, desenvolve o projeto de pesquisa "Os percalços da memória: migração e exílio no romance do século XXI”. E-mail: giniagomes@gmail.com.

${ }^{2}$ Doutora em Letras pela Universidade Federal do Rio Grande do Sul (UFRGS). Bolsista de Pós-Doutorado (PNPD-CAPES/MEC) junto ao Programa de Pós-graduação em Letras da UFRGS, com o projeto de pesquisa "Mulheres velhas: seus lugares e papéis na literatura brasileira do início do século XXI". E-mail: cristianesalves@gmail.com.
} 
de 22 anos de exílio, voltou para o Brasil, em junho de 1992, bem a tempo de assistir à deposição do presidente da república. Mais tarde, amparada pela Lei de Anistia, obteve reingresso na UFRGS e, em 2015, colou grau no curso de Letras, formando-se bacharel em tradução da língua francesa. Nesse mesmo ano, a editora Cosac Naify publicou seu livro de memórias, Volto semana que vem, vencedor do Prêmio Açorianos de Literatura 2015, na categoria narrativa longa. Nele, mesclando história, memória e ficção, a autora relata a sua trajetória de militância e prisão nos tempos de repressão, atravessando o Brasil, a Argentina e outros países. Atualmente, Maria Pilla é aposentada, trabalha como tradutora de francês e é Mestranda no Programa de Pós-graduação em Letras da UFRGS, na área de Estudos Literários Aplicados: Literatura, Ensino e Escrita criativa. Em razão da pandemia do Covid-19, que ainda nos assombra, a entrevista foi realizada por e-mail.

Entrevistadoras: Em primeiro lugar, diga-nos como se deu seu início na militância e de que forma essa vivência influenciou a pessoa que você é hoje.

Maria Pilla: Minha politização teve origem na década de 60, quando fui estudar nos Estados Unidos. Ela foi alimentada por muitas vertentes, mas a principal foi a guerra do Vietnã. Teve, também, a luta dos negros pelos direitos civis e a luta anticolonial dos países africanos. Walnut Hills era uma escola pública progressista com professores pacifistas, militantes da causa contra a guerra e pelos direitos civis dos negros. Nesta época, a música de Bob Dylan, de Joan Baez, de Peter, Paul and Mary, de Phil Ochs cantava um mundo melhor. O Vietnã era um cemitério de jovens americanos e os políticos pareciam não se importar. Neste contexto, nos EUA, comecei minha formação de militante, com a ajuda de amigos, dos livros e de professores. Estudando no Instituto de Educação em Porto Alegre $^{3}$, na época uma escola de valores ultraconservadores, não chegavam os ecos de um mundo que mudava; meu ingresso no Júlio de Castilhos $^{4}$ era muito recente para eu assimilar o ambiente politizado da escola.

\footnotetext{
${ }^{3}$ Instituto de Educação General Flores da Cunha, o mais antigo estabelecimento de ensino secundário e de formação de professores do Rio Grande do Sul. Tombado como patrimônio histórico estadual e municipal, está fechado para reformas desde 2016.

${ }^{4}$ Colégio Estadual Júlio de Castilhos, também conhecido como Julinho, localizado em Porto Alegre, RS. Fundado em 1900, é um dos mais tradicionais colégios da capital gaúcha. Até a primeira década dos anos 1980, foi considerado um colégio público exemplar, de reconhecida excelência de ensino. Palco de intensas manifestações estudantis, ajudou a formar as principais lideranças políticas e intelectuais do Estado. Por seus bancos passaram
} 
Me encontrava em Cincinnati quando houve o golpe no Brasil. A partir do retorno ao Brasil, é que ele adquiriu para mim a importância que tem hoje. Hoje, eu diria que ter frequentado na infância uma escola pobre, o Grupo Escolar Octavio Rocha, com alunos da vila Maria $\operatorname{degolada}^{5}$, no Partenon, foi o banho de Brasil que me levou para a esquerda definitivamente. Como na revolução francesa, a luta dos negros americanos foi acompanhada de um intenso movimento literário que preparava a cabeça da população para os líderes que iriam dirigir os futuros embates entre conservadores e um novo mundo por fazer. Penso em alguns deles: Toni Morrison, James Baldwin, Colson Whitehead. Na França: Choderlos de Laclos, Marquês de Sade. Então, sou feita de todos estes retalhos de acontecimentos e dos porta-vozes. O resultado é meu, mas a fonte é isto aí.

Entrevistadoras: O que você tem a dizer sobre a clandestinidade?

Maria Pilla: Viver na clandestinidade era viver com outra identidade. Vivi na clandestinidade, no exterior, com passaportes de outras nacionalidades e por este motivo perdi todas minhas referências nacionais, a língua em primeiro lugar. Foi o que mais me afetou. Meu companheiro naquele momento era um brasileiro que falava muito bem várias línguas; por razões de segurança, não falávamos português, nossas identidades eram europeias. Tínhamos que aparentar nossa origem estrangeira. Esse sistema era, portanto, completamente opressivo. Principalmente entre os militantes, nós deveríamos manter em segredo nossa nacionalidade verdadeira. Desnecessário dizer o difícil que era. Num procedimento médico, por exemplo, quando senti dor, gritei como fazemos - “ai!" -, reconhecível pelos dois médicos que me assistiam e que não sabiam minha nacionalidade até o grito. Era mega estressante, nem na dor era possível relaxar. Os médicos riram do meu intento de disfarçar as mil pistas que queria esconder de ser brasileira, tentaram me acalmar, dizendo que estava entre amigos etc., mas como ter confiança num país que caçava os militantes de esquerda?

Apesar de necessária, a clandestinidade foi o pior momento da minha vida, o mais pobre, o mais cerceador. Sabendo disso, é que se pode entender a felicidade que senti ao ser presa. Foi uma libertação, voltar ao que eu era, uma brasileira com a minha personalidade, a minha língua. A

nomes como Leonel Brizola, Paulo Brossard, Ibsen Pinheiro, Paixão Cortes, Barbosa Lessa, Moacyr Scliar e Luciana Genro entre outros.

${ }^{5}$ Vila Maria da Conceição, situada na periferia de Porto Alegre. Ficou conhecida como "Maria degolada" em razão de um crime ocorrido em 12 de novembro de 1899: a jovem alemã Maria Francelina Trenes, após uma discussão com seu amante, o cabo Bruno Soares Bicudo, foi morta por ele, tendo o pescoço cortado por uma faca. 
prisão supunha a tortura e isso, é claro, dava medo, pânico. Porém, passado este momento, quando fui levada a uma prisão e identificada como eu mesma, passei a dormir melhor, a perder o estresse da situação. E a ter confiança total nas minhas companheiras de celas.

Entrevistadoras: E sobre a experiência do exílio?

Maria Pilla: O exílio também chegou sem muitos avisos, mas foi rocambolesco quando veio. Em 1970, um grupo de militantes do POC de Porto Alegre tivemos que nos mudar às pressas para São Paulo. Fui com Flavio, meu companheiro na época. Estivemos morando na casa de muitos amigos, até que tive que morar sozinha na casa de uma amiga, em SP. Ela abrigava na casa alguns jovens hippies. Todo o santo dia cozinhavam arroz integral, que foi uma boa e má descoberta. Nunca mais consegui sentir o cheiro desta comida. Fato é que um dia a famigerada $\mathrm{OBAN}^{6}$ invadiu a casa dela e levou presos aqueles meninos. Por sorte, os demais moradores da casa se safaram. E foi este o episódio que nos lançou para fora do país. Nosso querido amigo e companheiro Marco Aurélio Garcia nos aconselhou firmemente a sair do país. Seguimos o conselho dele, pessoa de visão. Heloísa, minha amiga, tinha um pouco de grana para a passagem de avião, eu não. Então procurei amigos ou companheiros de militância, um por um, pedindo grana para sair do país. E fui amealhando um dinheirinho amarrotado de fundo de bolso. Levou tempo, mas consegui. Então passei a noite passando a ferro aquele mundaréu de trocado para irmos no dia seguinte comprar nossa viagem. Era um bolo de dinheiro bem chamativo. Acho que todos os cobradores de bonde e de ônibus não conseguiam bolo tão vistoso.

Botamos nossos pretinhos e colarzinho de pérola. Salto alto, claro. E partimos para uma agência de viagens. Eu tremia demais. Tínhamos decidido ir em companhias de aviação diferentes para o mesmo destino, Paris. Ela já tinha escolhido a Swissair e eu fiquei com a British Airways. Íamos para Paris! Mas eu sequer conseguia ficar feliz, de tão nervosa. Minha amiga fez toda a falação e a atendente era bem amável. Foi, até ver o bolo de dinheiro que coloquei no guichê para pagar minha passagem. Insistiu, então, com perguntas que não havia feito. Só ida, as duas? Ida e volta está em promoção. E por que não vão juntas? Morríamos de medo de que ela tivesse a ideia de chamar a polícia devido ao caso estranho diante dela. Não fez, contou o dinheiro e nos deu as passagens; tínhamos passaportes em dia e corretos. Os jornais alardeavam a saída de militantes para o exílio, daí o nosso temor. Vai que pensam que eram duas fugitivas com

\footnotetext{
${ }^{6}$ Operação Bandeirante. Organização criada em 1969, a fim de desmantelar as organizações de esquerda.
} 
malfeitos por aí. Nossas fotos não estavam em cartazes e isso era uma grande ajuda. Assim começou.

Meu status de asilada me proporcionava direitos elementares para minha estadia no país. Em primeiro lugar, a documentação: a carte de séjour (carta de estadia, o documento básico para permanecer no país e trabalhar), a carta de trabalho, o passaporte de refugiados e apátridas da ONU, benefícios como os tickets de metrô/ônibus, alguns cursos de formação gratuitos, um curso básico de francês na Aliança Francesa. Fiz também um curso numa escola exclusiva de Jornalistas, financiado pelo Secours Catholique ${ }^{7}$. Na realidade, as agências governamentais de formação de mão de obra começaram a funcionar quando houve a informatização do país, mas aí eu escolhi fazer esta formação com minhas colegas da cooperativa que comecei a trabalhar à época. Então, minha inserção se deu no mundo do trabalho e não acadêmico. Trabalhando em uma indústria gráfica, convivi com as mais variadas falas do país. De Marguerite Duras, cliente da nossa cooperativa (ela fazia uma revista), a jovens motoqueiros (bons de gíria) tradicionalmente empregados na montagem dos jornais e revistas que fazíamos.

Quando a cooperativa terminou em 84 , trabalhei como frila em jornais e revistas, fazendo a parte técnica. Sendo trabalhos sazonais, o pagamento era excelente, mas as cadências de trabalho, o ritmo, era acelerado. Nesta época, Duras fazia sua revista com Butel, um jornalista que pagava bem seus funcionários (eu era da equipe, graças a minhas amigas cooperativadas) mas tinha o defeito de levar para as reuniões das revistas suas ex, que brigavam diante de todos (meu francês melhorou por demais) e, via de regra, botavam em xeque a sobrevivência da revista. Foram vários números da revista assim, até que retornei. E antes que me perguntem por que troquei Paris por Porto Alegre e depois Viamão, o motivo foi estar com minha mãe nos últimos anos de vida dela, a pessoa que mais admirei e gostei na vida. Ela, que sempre me apoiou, me incentivou, que passou de um universo conservador para um de sufragette e de eleitora do PT.

Meu exílio não foi nada dourado, mas tive fantásticas experiências de vida (Graças a deus). Muito tempo à procura de trabalho, tive todos os namorados imagináveis e inimagináveis, também as separações, as choradeiras, todas as tristezas do mundo, poucos momentos depressivos, que não sou dada a isto. Frequentei unicamente o mundo do trabalho francês, numa época de desemprego alto. Então, manter o emprego era questão de vida ou morte; mesmo ganhando corretamente, o custo de vida em Paris só era comparável ao de Roma e Tóquio. Um

\footnotetext{
${ }^{7}$ Serviço da Igreja Católica na França, que tem como missão atender pessoas em dificuldade, lutando contra a desigualdade e a exclusão social.
} 
horror! Entre achados e perdidos, me separei e me casei com um francês, do qual também me separei. Ao contrário do jornalista Michel Butel, mantenho até hoje boas relações de amizade e carinho com os ex.

Entrevistadoras: Parece, pela leitura do seu livro, que as lembranças do tempo na prisão, apesar de tudo, são positivas. Poderia nos explicar se e como isso é possível?

Maria Pilla: A prisão foi para mim e minhas companheiras do cone sul uma experiência única. Nós, as presas é que fizemos com que fosse assim. O projeto da ditadura era o oposto. Desde o começo, entendemos que tudo ali estava feito para nos destruir. Como ali não havia ninguém que se achasse merecedora do tratamento que nos estava destinado, criamos uma prisão só nossa, se se pode dizer. A primeira luta foi manterem abertas as portas das celas, já que tinham nos encerrado cada 4 presas em pequenas celas de $3 \mathrm{mx} 3 \mathrm{~m}$, sem banheiro. A ideia deles era manter um pavilhão de umas 90 mulheres presas, em pequenas celas sem banheiro, com idas ao banheiro controladas de uma a uma pelas carcereiras. Este sistema não podia funcionar. Tanto mais que havia algumas crianças de colo. A gritaria foi imediata com a última volta da chave: "preciso ir ao banheiro, por favor". As carcereiras pareciam baratas tontas. Não havia porta nem chave para atender os pedidos. Já no começo da tarde, as celas foram abertas e ficamos no controle do pavilhão. As autoridades da cadeia não conseguiam sequer ter uma proposta "normal" de organização da repartição das refeições, o que para nós era de uma simplicidade franciscana: mesas e bancos dispostos no corredor, o grupo de faxina, encarregado das tarefas de limpeza e repartição da comida na semana, servia cada prato que era repassado de mão em mãos às presas, que comiam com seus respectivos talheres de metal "emprestados" pela cadeia (eram contados antes de comer e ao final da lavagem). Desse modo, a comida recebida em grandes panelões era dividida entre todas. Diferentemente de algumas prisões brasileiras, na Argentina as presas comuns cozinhavam para as políticas por razões de segurança. Na Argentina não queriam presas políticas circulando pela prisão, "reconhecendo" o prédio e, eventualmente, preparando fugas. Ao controlar os pavilhões de presos, os políticos inverteram uma lógica focada na destruição psicológica em outra — na medida do possível, é claro - de luta pela vida e saúde de todas. Vejamos, a seguir, como isso aconteceu.

O tempo de cárcere era ocupado com um máximo de atividades criativas, físicas, a maior parte coletivas. Antes do café da manhã ( $8 \mathrm{~h}$ ou $8 \mathrm{~h} 30$ ), havia um ateliê de trabalhos manuais com o objetivo de fabricar peças a serem vendidas pelas associações de familiares e cuja venda revertia 
em itens de alimentos para melhorar nossas condições físicas e mentais naquele lugar (queijos grandes, barras de chocolate, selos para correspondência, maços de cigarros, frutas); todas participavam desta atividade. Logo após, no horário do recreio (a saída de todas a um pátio ao ar livre), havia uma grande atividade de ginástica dos pavilhões. As organizações armadas encaravam esta ginástica como uma preparação física para quando houvesse retorno da luta armada. Quando perceberam isso, os militares enviavam oficiais para assistirem e anotarem os exercícios do alto do telhado da prisão. Com efeito, não era uma ginástica qualquer. De retorno ao pavilhão, tínhamos aulas de idiomas: inglês, francês, português e de alfabetização para as analfabetas.

Depois do almoço, o penal nos obrigava a uma sesta de uma hora nas respectivas celas; era quando aproveitávamos para ler, entre as quatro presas de cada cela, a imprensa escrita, o jornal La Nación, o único permitido, o mais conservador de todos, apesar da excelente imprensa do país. O jornal circulava de tal modo que as presas liam a edição do dia apenas uma vez ao mês. Mesmo a leitura dos jornais velhos não era desperdiçada: mensalmente nos reuníamos na grande cela para ouvir a exposição de cada um dos grupos que faziam a leitura do jornal (internacional, nacional, movimentos sociais e aqui uma particularidade argentina, "el accionar militar" das organizações armadas da oposição - Montoneros, PRT e outras. O final da tarde, se bem lembro, era "livre" para leitura e outras atividades. Lembro de uma exposição sobre a guerra do Líbano em que criamos (com a memória de todas) um grande mapa da África com papel jornal para localizar as cidades libanesas onde a guerra civil devastava a população. Com o que tínhamos, criávamos grandes discussões sobre a realidade nacional e internacional. Exagerando, éramos nossa própria internet. Permitiram a algumas celas a posse de um radiozinho onde escutávamos a famosa Radio Colônia do Uruguai que, fundamentalmente, noticiava algo da ditadura argentina e da ação das organizações armadas. Em 1976, o golpe caçou esta fonte e nosso rádio foi confiscado para sempre. Continuando sobre as atividades das presas, aos fins de semana os grupos de limpeza, distribuição das refeições e lavagem da louça (nos organizamos em grupos de dez, que se revezavam durante o mês para estas tarefas) organizavam grandes passatempos para todas as presas, onde houvesse espaço (no corredor do pavilhão, na grande cela). Eram peças de teatro, musicais, um arremedo do que ocorria no país e a nós. Talentos se escondiam naquela massa de presas; as horas passadas ali eram muito divertidas; as sessões eram aguardadas com bastante expectativa pelas presas.

Neste quotidiano havia uma surpreendente explosão de criatividade para desarmar o ódio que se abatia sobre nós. Decididamente, as presas de Olmos, depois de Devoto, não aceitavam para 
si o sombrio epíteto de terroristas. Havia uma forte solidariedade entre as presas; as especialmente perseguidas eram apoiadas pelo conjunto, inclusive com greve de fome. Havia entre nós uma advogada que defendia uma causa de sindicatos classistas da cidade de Rosário. Doente com uma úlcera no duodeno, esta moça nos foi entregue pesando 48 quilos. Ela mal conseguia manter-se em pé. Nos quartéis em que esteve detida não lhe ministravam a medicação necessária. Chegando em Olmos, tentaram seguir com o mesmo tratamento. Após tentarmos fazer funcionar nossa diplomacia de enviar a delegada do pavilhão e, com a resposta negativa, nos organizamos e iniciamos uma greve de fome, uma medida para casos extremos, que felizmente durou pouco. A greve de fome é o que mais desorganiza uma prisão. Os chefes entram em pânico. A notícia é um rastilho de pólvora. A comida não consumida é jogada no lixo, os vizinhos denunciam o mau cheiro. O pessoal militar inferior se agita mais da conta, enfim, é um inferno para os chefões. Ela é ruim para todos. É difícil unir os presos em torno de medida tão radical e arriscada para todos, mesmo nestes casos.

Foi assim que todas saíram ilesas, ninguém perdeu o juízo, mesmo vivendo anos no limite. Mantivemos o ar galhofeiro da chegada. Algumas, quem sabe, até hoje. Que sorte. Quando vou a Buenos Aires, costumo encontrar algumas delas. Avenida Corrientes abajo, de braços dados, nossas risadas abafadas pelas buzinas dos carros, a fumaça dos ônibus apagando nossas fisionomias, somos as sobreviventes contando a história para que nunca mais.

Entrevistadoras: Descreva o momento em que começou a escrever o seu livro. Havia alguns diários daquela época ou todo o material é recente?

Maria Pilla: O Volto começou com uma vaga ideia de contar o que havia vivido na militância, aqui e na Argentina, duas ditaduras militares. De algum jeito, eu achava importante mostrar a jovens dispostos a ouvir as consequências dos militares no governo. Mas devia contar de um jeito que não suscitasse resistências pelas violências físicas que sabiam existir. $\mathrm{Na}$ época da ocupação da $\mathrm{UFRGS}^{8}$, ao final dos muitos debates em que fui para falar da época, vieram me contar que começaram a ler o livro temendo encontrar as histórias de tortura que ouviram falar e me agradeciam de certa forma a abordagem encontrada. Eu já tinha a ideia dos capítulos curtos como fragmentos em que acontece a memória. Pedaços de vivências selecionados pelo fluir das

\footnotetext{
${ }^{8}$ Iniciada por estudantes contrários ao Projeto de Emenda Constitucional (PEC) 55/2016 (antes PEC 241) e à Medida Provisória (MP) 746/2016 de Reforma do Ensino Médio, que tramitaram durante o governo de Michel Temer. A primeira ocupação, na UFRGS, ocorreu no prédio do curso de Letras, em 26 de outubro de 2016. Posteriormente, outros cursos aderiram ao movimento.
} 
lembranças. E foi assim que comecei a escrever as primeiras páginas com a história dos uniformes. Seguiram outras até que enviei por e-mail ao prof. Fischer. Silêncio de alguns dias. Pensei, ih, deve ter detestado. Até que veio o e-mail dele, dizendo que eu não parasse de escrever etc. Foi curto, mas estimulante. Nas semanas seguintes, conforme escrevia algum capítulo, tomei coragem de mostrar a outros profes do cafezinho, como o prof. Homero. Homero também gostou à maneira dele, que eu já conhecia das aulas. Lembro que a história do peso das melancias surpreendeu a todos. Como pode um não problema suscitar tanta celeuma. Parei de mostrar os textos e continuei meus capítulos, já imaginando um eventual livro e me dizendo que se mostrasse tudo, eles não teriam o que ler depois. Lá pelas tantas, Fischer começou a falar em livro e eu já ficava bem assustada com a responsa do tal livro. É que vocês não sabem, mas sou muitíssimo tímida, avessa a essas coisas públicas, gente olhando etc. Sou insegura, muitas vezes, e não sou quando deveria ser. E foi assim, sem muito glamour que o Volto nasceu. Eu gostaria tanto que o Volto ajudasse alguns jovens a não papagaiarem os slogans da volta à ditadura... Poxa, custou tanto à minha geração lutar contra uma ditadura feroz, que matou de maneira atroz tantas pessoas... É o que eu gostaria, mas talvez não dê.

Entrevistadoras: Além das suas experiências, dos episódios que vivenciou, a que outras fontes você recorreu para compor o livro?

Maria Pilla: Nenhuma. No Volto, usei apenas minhas memórias e recorri à internet para confirmar os dados de alguns capítulos ligados à atuação da repressão, como a Noite dos Lápis.

Entrevistadoras: Conte-nos a respeito da recepção de seu livro. Surpreendeu-a a boa acolhida, o fato de ter sido (e seguir sendo) objeto de estudos e vir suscitando interessantes reflexões?

Maria Pilla: Embora eu esperasse que o livro trouxesse alguma discussão sobre a ditadura (ele foi escrito quando o bolsonarismo botava a cabeça de fora elogiando a tortura, o regime ditatorial, pedindo o AI-5), nunca pensei que teria a repercussão que teve. O Volto não foi o único: outras obras apareceram para falar da mesma época. $\mathrm{O}$ momento ajudou bastante. Foi a época das ocupações; na UFRGS, muitos alunos e alguns professores mantinham uma atmosfera de agitação. Estive em numerosos debates sobre o livro que, rapidamente, se transformavam em debates sobre a ditadura. Creio mesmo nunca ter discutido o livro propriamente dito; ele era um trampolim para outras inquietações dos alunos e professores. 
Depois da UFRGS, estive em outras universidades (Brasília, Universidade de Rio Grande) e aí o tema era abertamente a ditadura cívico militar de 1964. Tudo isso me dá uma enorme satisfação porque carecemos de discussões sobre a história recente do país; o conservadorismo da nossa sociedade sempre manteve o conveniente véu da ignorância da nossa história para os brasileiros. Graças a isto, uma anistia manteve impunes os crimes da ditadura, da mesma forma que congela toda discussão sobre temas de interesse geral da população, como o direito das mulheres ao aborto e a uma política pública de planejamento familiar.

Entrevistadoras: O que você tem a dizer sobre o aumento recente de produções de autoria feminina que, assim como no seu caso, evidenciam o protagonismo da mulher nos enfrentamentos histórico-políticos, não apenas como companheiras de personagens masculinas, mas como partícipes diretas, atuantes?

Maria Pilla: Nós mulheres temos um longo caminho pela frente, temos que aprender a olhar pra vida, pro mundo, sem medo, como fazem os homens. As novas gerações são menos encucadas, basta olhar os cartazes que fazem nas manifestações. Reivindicam o absoluto direito de decidir sobre seu corpo. E apontam com o dedo: "el violador es tu", no impressionante protesto das mulheres chilenas, que é de todas nós. Assumir um protagonismo (que é um crescimento), é nossa obrigação para exigir respeito como mulheres e cidadãs. Menos que isso é manter o patriarcado.

Entrevistadoras: Finalmente, antes de encerrar a entrevista, agradecemos muito pela sua disponibilidade e generosidade e, aproveitando o espaço, gostaríamos que comentasse sobre os livros de que gosta e, também, alguns títulos que considera fundamentais para termos na estante.

Maria Pilla: Eu estaria feliz se escrevesse parecidamente com um escritor de minha admiração, o siciliano Leonardo Sciascia, um professor de escola que foi deputado pelo Partido Comunista italiano. Amo de paixão (sou exagerada mesmo) o livro Yo el Supremo, do paraguaio Augusto Roa Bastos, sem deixar de me deliciar com os contos do Cortázar, do Borges; os argentinos Roberto Arlt e Adfolfo Bioy Casares; os uruguaios Benedetti e Onetti, Raymond Carver. Adoro contos. "O gato", do Poe, até hoje me dá arrepios. Ando sem paciência para textos longos.

E, quando criança, adorei o Tom Sawyer e o Huckleberry Finn, do genial Mark Twain. $O$ apanhador no campo de centeio fez a minha cabeça de adolescente e sempre presenteio jovens 
com este livro. Ah! Fui leitora incansável do bravo Eça de Queiroz. Que lindo humor ácido tem ele! Tive a sorte de ter quem me alcançasse algum livro merecedor de atenção pela inteligência/rabugice. Notarão a ausência de brasileiros. É claro, como podia ser diferente? Nem sempre se tem uma livraria brasileira por perto. Mas posso dizer que o Caio Fernando foi uma baita descoberta. 